\title{
Recognition of Professor Thomas Brandt
}

\author{
Gérard Said
}

Published online: 22 December 2010

(C) Springer-Verlag 2010

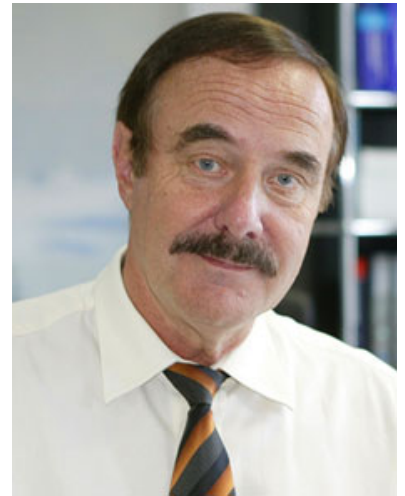

Professor Thomas Brandt is leaving the editorship of the Journal of Neurology. Originally founded in 1891 by Wilhem Heinrich Erb, as Deutsche Zeitschrift für Nervenheilkunde, the name then changed to Zeitschrift für Neurologie (Journal of Neurology) when Marco Mumenthaler was editor. In 1991 the Journal of Neurology became the official journal of the European Neurological Society (ENS), and in 1994 the language switched from German to English to become an internationally recognized journal. Since then, its reputation and impact factor have grown steadily along with the number and the scientific level of papers submitted for publication. The strong links that the Journal of Neurology now has with the ENS are illustrated the contribution of former Presidents of the ENS to the journal. Professors Alastair Compston, Jan Van Gijn, and Thomas Brandt all served both as President of the ENS and

\section{G. Said ( $\square)$}

Féderation de Neurologie, Hôpital de la Salpétrière, 47 bd de l'Hôpital, 756541 Paris Cédex 13, France e-mail: grrdsd@gmail.com
Chief Editors of the journal and participated as a co-editor of the journal at the meetings of the Executive Committee of the ENS.

Professor Thomas Brandt has now completed 10 years as co-editor of the journal. Under his tenure, the impact factor of the journal has reached 3 , with an improvement in design and clarity. The journal, which is now more oriented towards clinical neuroscience, remains very much focused on clinical neurology and management of patients. In this respect, Professor Brandt concentrates all the qualities and expertise for a fruitful transition between neuroscience and clinical neurology. Professor Brandt represents the epitome of traditional European expertise in clinical neurology and neuroscience. He is a renowned clinician and a world famous expert in neurovestibular disorders, eye movement disorders, balance, and control of movement. $\mathrm{He}$ is a remarkable teacher. I personally did my best to attend his teaching courses at the ENS as often as possible, to see again and again how he examines a patient who complains of vertigo, to identify the mechanism of the symptoms, and often to alleviate the burden by simple methods. Professor Brandt was especially talented at being able to show how simple a complicated neurological syndrome can be in his hands.

Professor Thomas Brandt's expertise, however, goes much further than patient management. He was able to perform sophisticated investigations including functional MRI or PET scans to clarify the pathophysiology of a number of complex vestibular functions and movement disorders. His approach should remain an example to younger neurologists: clinical manifestations must direct the investigations. In this respect, Professor Thomas Brandt illustrated how to make the link between clinical neurology and modern techniques of investigations. His academic record is no less remarkable. After medical studies at the 
University of Essen, Thomas Brandt received his postgraduate training at the Department of Neurology and Clinical Neurophysiology with Professor R. Jung at the University of Freiburg where he worked on interactions between the visual and the vestibular systems in perception of motion. Being honored with numerous awards from scientific societies during his academic career, he has also been invited to lecture on the neurovestibular system throughout the world.

Professor Thomas Brandt was Director of the Neurological Clinic in Munich (1984-2008) which became a world renowned center for the study of neurovestibular disorders. Since 2008, Professor Brandt has been the Chairman and Director of the Institute for Clinical Neurosciences in Munich. During the many years we have collaborated at the ENS and as co-editor of the journal, I have very much appreciated his professionalism, friendship, and sense of humor. In addition to all these qualities, Professor Thomas Brandt not only has time to be a talented sculptor but he also remains very close to his wife and children. The ENS, the Journal of Neurology, his family, his colleagues and his friends are all lucky to have him at their side. 